\title{
La carga viral y el recuento de CD4 también son útiles en niños con infección por HIV
}

Predictive value of quantitative plasma HIV RNA and CD4 lynphocyte count in HIV infected infants and children. Palumbo P, Raskino C, Fiscus S, et al. JAMA 1998; 279:756-761

\section{Objetivo}

Evaluar el valor pronóstico de la carga viral (CV) y el recuento de linfocitos CD4 en niños HIV positivos. Establecer los valores para lograr óptimos resultados clínicos

\section{Diseño}

Cohorte anidada en un ensayo clínico controlado aleatorizado y doble ciego(1).

\section{Lugar}

Datos del estudio ACTG 152 (eficacia de zidovudina y didanosina solas o combinadas en 831 pacientes sintomáticos de 3 meses a 18 años de edad con menos de 6 semanas, o vírgenes de tratamiento antiretroviral).

\section{Pacientes}

Se seleccionaron los 566 pacientes cuyas muestras basales estuvieron disponibles. La distribución de las edades, sexo, mediana de los CD4 y grupo terapéutico asignado de estos pacientes fue similar al total de los del estudio ACTG 152.

\section{Evaluación de factores pronósticos}

Se evaluó mediante análisis de sobrevida* el valor de la CV y de los CD4 al inicio del estudio y luego de 24 semanas de tratamiento antiretroviral, para predecir la sobrevida libre de progresión de la enfermedad (SLPE) a los 2 años.

\section{Medición de resultados principales}

Los puntos finales fueron la muerte o el tiempo a la primera manifestación de progresión de la enfermedad definida como fracaso en el crecimiento, alteración en el neurodesarrollo o infecciones oportunistas.

\section{Resultados Principales}

La CV y los CD4 fueron buenos predictores $(p<0,001)$ mejorando con el uso combinado.

\begin{tabular}{|c|c|c|c|c|c|c|c|}
\hline \multicolumn{3}{|c|}{ Basal } & \multicolumn{5}{|c|}{24 semanas post-tratamiento } \\
\hline Edad & CD4(\#) & $\mathrm{RNA}(=)$ & $\operatorname{SLPE}(\&)$ & Edad & CD4(\#) & $\mathrm{RNA}(=)$ & $\operatorname{SLPE}(\&)$ \\
\hline \multirow[t]{4}{*}{$3-12 m$} & $<1000$ & =1 millón & $64 \%$ & $<36 \mathrm{~m}$ & $<500$ & $=10.000$ & $100 \%$ \\
\hline & & $>1$ millón & $34 \%$ & & & $>10.000$ & $38 \%$ \\
\hline & $=1000$ & =1 millón & $89 \%$ & & $=500$ & $=10.000$ & $97 \%$ \\
\hline & & $>1$ millón & $67 \%$ & & & $>10.000$ & $76 \%$ \\
\hline \multirow[t]{4}{*}{$12-30 m$} & $<500$ & $=200.000$ & $88 \%$ & $3-6,5 a$ & $<500$ & $=10.000$ & $100 \%$ \\
\hline & & $>200.000$ & $45 \%$ & & & $>10.000$ & $55 \%$ \\
\hline & $=500$ & $=200.000$ & $91 \%$ & & $=500$ & $=10.000$ & $96 \%$ \\
\hline & & $>200.000$ & $87 \%$ & & & $>10.000$ & $97 \%$ \\
\hline \multirow[t]{4}{*}{$30 m-6 a$} & $<500$ & $=100.000$ & $70 \%$ & $6,5-18,5 a$ & $<<200$ & $=10.000$ & $67 \%$ \\
\hline & & $>100.000$ & $57 \%$ & & & $>10.000$ & $45 \%$ \\
\hline & $=500$ & $=100.000$ & $100 \%$ & & $=200$ & $=10.000$ & $97 \%$ \\
\hline & & $>100.000$ & $94 \%$ & & & $>10.000$ & $88 \%$ \\
\hline \multirow[t]{4}{*}{$6-18 a$} & $<200$ & $=50.000$ & $47 \%$ & \multirow{4}{*}{\multicolumn{4}{|c|}{$\begin{array}{l}\text { (\#) Recuento de CD4/mL. } \\
\text { (=) Copias/mL (método Nasba) } \\
\text { (\&) Pacientes sin progresión de la en- } \\
\text { fermedad a los } 2 \text { años de seguimiento. }\end{array}$}} \\
\hline & & $>50.000$ & $41 \%$ & & & & \\
\hline & $=200$ & $=50.000$ & $98 \%$ & & & & \\
\hline & & $>50.000$ & $90 \%$ & & & & \\
\hline
\end{tabular}

\section{Conclusiones}

En pacientes pediátricos HIV positivos la CV y los CD4 son predictores independientes del curso clínico. La tasa de progresión de la enfermedad a 2 años es menor al $5 \%$ si la CV es menor a 10.000 copias/ml y los CD4 son más de 500/ml en menores de 6,5 años y más de $200 / \mathrm{ml}$ en mayores de esa edad.

La relación lineal, independiente de la edad entre la $\mathrm{CV}$ y el riesgo relativo de progresión de la enfermedad, respalda todos los esfuerzos terapéuticos para alcanzar niveles virales plasmáticos tan bajos como sea posible.

\section{COMENTARIO}

Este estudio avala el poder de dos marcadores de laboratorio, para predecir la progresión de la enfermedad, respaldando los tratamientos enérgicos para disminuir la carga viral plasmática a no más de 10000 copias/ml y mantener el nivel de CD4 alejado del compromiso inmunológico severo.

La Sociedad Argentina de Infectología y la Sociedad Argentina de SIDA (2) recomiendan iniciar antiretrovirales en todos los menores de 1 año; en niños sintomáticos o con compromiso inmunológico; y en los mayores asintomáticos con CV 5000-10000 copias/ml (método bDNA) ó CV 10000-20000 (método Nasba) en quienes se use como único criterio la carga viral.

Si bien cada vez hay más tratamientos para alterar el curso de la infección por HIV, los esfuerzos, deben estar destinados a prevenirla. La transmisión vertical, modo principal de adquisición de la infección en la infancia es del 15 al 40\%. La detección del HIV en mujeres fértiles o gestantes, posibilita reducir la probabilidad de infección en el recién nacido. El estudio ACTG076 demostró que la transmisión puede reducirse significativamente de un 22,6 a un $7,6 \%\left(R^{*}{ }^{*}=66 \%\right)$ con mínima toxicidad materno-infantil. Esto se logró con un régimen de AZT oral dado a las embarazadas con CD4 200 desde la semana 14-34 de gestación, AZT intravenoso durante el parto y AZT oral al recién nacido durante las primeras 6 semanas de vida $(3,4)$. El análisis preliminar del estudio ACTG185, que agregó al AZT, inmunoglobulina standard o hiperinmune (altos niveles de anticuerpos anti-HIV) en embarazadas con enfermedad avanzada (bajos recuentos de CD4), dió por resultado una tasa de transmisión del 4,8\%.(5)

Si deseamos que el SIDA pediátrico disminuya en nuestro país, el rastreo en las embarazadas debe dejar de ser una conducta individual, ya que diferentes estudios avalan la quimioprofilaxis con AZT para reducir la transmisión vertical. Este estudio sustenta el esfuerzo en disminuir la CV para reducir el riesgo de progresión de la enfermedad, cuando ha fracasado el intento de prevención primaria.

*Ver glosario

\section{Referencias}

1. Enclund J, Baker C, Raskino C, et al. For the AIDS Clinical Trials Group (ACTG) Study 152 team. Zidovudine, didanosine

or both as the initial treatment for symptomatic Hiv-infected children. N Eng J Med 1997;336:1704-12

2. SADI (Sociedad Argentina de Infectología) - SAS (Sociedad Argentina de SIDA). Recomendaciones. 1997

3. Connor E, Sperling R, Gelber R, et al. For the Pediatric AIDS Clinical Trials Group Protocolol 076 Study Group (PACTG 076). Reduction of maternal-infant transmission of human immunodeficiency virus type 1 with zidovudine treatment. N Engl J Med 1994;331:1173-80

4. Sperling R, Shapiro D, Coombs R et al, Maternal viral Load, zidovudine treatment, and the risk of transmission of human immunodeficiency virus type 1 from mother to infant. N Engl J Med 1996;335:1621-9 5. U.S: Department of health and human services.CDC. Morbidity and mortality weekly report (MMWR). Public Health Service Task Force. Recommendations for the Use of Antiretroviral Drugs in Pregnant Woman Infected with HIV-1 for Maternal Health and for Reducing Perinatal HIV-1 Transmission in the United States.January 30, 1998. Vol 47. No. RR-2
Dra. Paula Andrea Chávez Hospital de Niños Ricardo Gutiérrez 